\title{
Twin Cities truck traffic management strategies
}

\author{
T. H. Maze ${ }^{1} \&$ R. Gale \\ ${ }^{1}$ Center for Transportation Research and Education, \\ Iowa State University, Ames, Iowa, USA \\ ${ }^{2}$ Minnesota Department of Transportation, \\ Office of Freight and Commercial Vehicle Operations, Minnesota, USA
}

\begin{abstract}
Heavy commercial vehicles have significantly different vehicle performance characteristics than light vehicles, and generally have different trip patterns (both spatially and temporally). As a result, the special needs of heavy commercials are not always met by standard roadway and facility designs, traveller information, and roadway operating/management process. The purpose of the research described in this paper was to investigate the traffic management strategies that could be applied in the Twin Cities metropolitan area of Minneapolis/St, Paul, MN, to improve truck traffic transportation within the area, and to develop implementation plans for applying the strategies. All the strategies recommended are relatively low cost, represent marginal improvements, can be feasibly accomplished within a few years, and require no special financial appropriation. The investigators were surprised that the most promising strategies involved only low-cost or no-cost policy change as opposed to high capital costs infrastructure or design improvements.

Keywords: truck traffic, traffic management, urban freight, truck facility improvements, Minneapolis/St. Paul, traffic congestion management.
\end{abstract}

\section{Introduction}

All USA major metropolitan areas have a planning process to identify and plan transportation systems improvements over time. Generally, it is assumed that those improvements that enhance transportation mobility (congestion relief and accessibility improvement) and enhance safety, will positively impact all 
vehicles in the traffic stream and improve the passenger and freight carrying capacity and safety. Generally, improvements to the system that reduce congestion and improve safety, reduce transportation costs for all use. Heavy commercial vehicles have different performance characteristics than other segments of the general vehicle fleet, and often have different travel patterns (both spatially and temporally) than general traffic. These differences are generally taken into account by making a heavy vehicle the design vehicle for infrastructure and, thereby, over-sizing facilities or providing more structural capacity than would be required if highways were to only carry light vehicles. However, it is not always the case that the infrastructure needs, the operational requirements, and traveler informational needs of heavy commercial vehicles are taken into account in facility plans, development, and operation. Therefore, by looking at the special needs of heavy commercial trucks, improvement can be identified that support management of truck traffic.

In 2004, the Minnesota Department of Transportation (Mn/DOT) initiated a study with the support of the Center for Transportation Research and Education (CTRE) at Iowa State University (Maze et al. [1]). The purpose of this project was to identify strategies that will reduce congestion for trucks traveling within and through the Twin Cities. National Cooperative Highway Research synthesis report 314 (NCHRP 314 [2]) identified a number of improvements that state transportation agencies have implemented, or are planning to implement, that focus on the unique needs of trucks to better accommodate truck-borne freight traffic. Additionally, to help reduce delays and congestion, a few other urban areas have conducted studies of the unique issues trucks face. The investigators identify strategies described in NCHRP 314, in truck studies in other urban areas, strategies identified during the research, and define how these strategies would be applied in the Twin Cities and develop implementation plans for the most promising.

\subsection{The Twin Cities}

The Minneapolis-St. Paul metropolitan area was estimated to have a population of almost 3 million in the 2000 census, and is the 15th largest metropolitan area in the U.S. Even though the Twin Cities are more than 1,000 miles away from an Atlantic port, and more than 1,500 miles away from a Pacific port, the Twin Cities ranks $8^{\text {th }}$ among U.S. metropolitan areas in terms of export sales and first in processed agricultural goods exported (Minnesota Department of Trade and Economic Development [3]). Many of the Twin Cities' largest exporters are high tech exporters offering high paying and highly mobile jobs. For the Twin Cities to continue to be home for these mobile industries, and for the Twin Cities to be the base for companies to compete and be successful in world markets, efficient goods movement within and through the area is critically important.

"The 2004 Urban Mobility Report," prepared by the Texas Transportation Institute [4] reports on congestion in the nation's urban areas and found that the Twin Cities metro area is one of the most congested areas for its population size in the United States. When the Twin Cities are compared to urban areas of similar population size, the total delay (travel time above what it takes to 
complete a trip at free-flow speeds) falls in the top 25 percent of the most congested of its peer urban areas. What is even more troublesome is that the growth in the congestion in the Twin Cities metro area places it in the top 20 percent of its peer urban areas. Hence, the unfortunate trend is that the Twin Cities is more congested than most of its peer urban areas, and the Twin Cities is getting increasingly more congested at a faster rate.

The high and the quickly increasing congestion, means that the cost of doing business in the Twin Cities is increasing faster than in comparable urban areas. It takes longer to ship inbound and outbound goods by truck and transit times for trucks are less reliable. This places the Twin Cities at a competitive disadvantage when firms compare the cost of doing business in the Twin Cities against costs of doing business in other cities. The objective of this project is to identify strategies that can be employed to help reverse this trend.

\subsection{Summary of findings}

The project was conducted through a series of iterative steps. First, to make sure that all reasonable potential strategies were considered, the research gathered strategies broadly from the literature and through interviews with Twin Cities' transportation professionals. The next step involved winnowing the possible strategies down to those that were the most promising. The final stage of the research was to develop a discussion of the issues related to the most promising strategies and issues associated with their implementation. While most of the strategies selected were low costs, some faced significant institutional barriers. One of the most promising strategies even requires the passing of new legislation. For each strategy, the document laid out implementation strategies.

\section{Strategies investigated}

The most common process for solving an engineering problem is to first identify the deficiencies and define the parameters of those deficiencies, second to identify alternative solutions that address the deficiencies identified, third to measure the benefits and costs of each solution, and last, to select the preferred option. However, in this case, the search for strategies was more broadly defined and out of the forty plus strategies identified in NCHRP 314 and the additional strategies identified through the research process, the researchers were to identify the most promising strategies that could be broadly applied to the highway system in the metropolitan area to reduce truck traffic congestion. The objective was not to find specific locations or projects, but rather to find strategies that the State Transportation Agency and partner transportation agencies could apply in the future.

Interviews were conducted with several Twin Cities' transportation professionals, and a survey was conducted of the truck firm members of the Minnesota Trucking Association to determine additional strategies and to test the feasibility of strategies already identified. Ultimately, the researchers winnowed 
down the possible strategies to 30 that could be feasibly applied in the Twin Cites. These were categorized into the following four categories:

- Operational strategies. Strategies that involve traffic operation and management solutions to reduce or mitigate truck-related congestion.

- Driver-oriented strategies. Issues that focus on providing drivers with better or more information and strategies that allow truck operators to better perform their driving.

- Capital investment strategies. Strategies that involve the construction of new facilities to improve truck traffic movements and congestion.

- Planning strategies. Strategies that focus on improvements to planning or changes in institutional or legal systems that will result in better capital programs or in operations resulting in reduced truck-related congestion.

\subsection{Candidate strategies}

From the 30 feasible strategies, seven more strategies were eliminated by the researchers because the strategy was already being employed by another Twin Cities entity, there were significant institutional barriers to the employing the strategies, or they did not appear to provide a desirable benefit to cost ratio. The remaining 23 strategies were prioritized through a workshop with public and private sector transportation professionals, enforcement officials, and motor carrier representatives.

\subsubsection{Candidate operational strategies}

Four of the candidate strategies were categorized as operational strategies and included the following:

- Restricting trucks to the right lanes of freeways with more than three lanes in each direction.

- Intersection detection of large vehicle and signal prioritization for heavy trucks.

- Allow trucks to use under utilized high occupancy vehicle (HOV) lanes.

- Allow trucks to use HOV and Bus bypasses around ramp meters.

\subsubsection{Candidate driver oriented strategies}

By far, the most candidate strategies focused on providing better information to truck drivers. The eight candidate driver oriented strategies were:

- Improve guide signs on multilane arterials streets directing vehicles to the appropriate lane for a freeway ramp.

- Create traveller information and information delivery systems specifically focusing on long distance travellers.

- Improve and create larger directional signage for truck-oriented facilities.

- Implement dynamic curve warning devices at locations on the Twin Cities freeway system where trucks are known to over-turn.

- Create a map or maps indicating the locations of roadway hazards (e.g., low bridges, narrow roadways, etc.) for large trucks 
- Create a map of the Twin Cities indicating the location of truck-oriented facilities (e.g., truck stops, truck permitting office, weight restrictions on roadways, etc.)

- Integrates local roadway construction and restriction information into the State Transportation Agency's Internet information system

- Use Citizen Band (CB) radio to deliver traffic information to truckers

\subsubsection{Candidate capital strategies}

There were seven candidate capital strategies. These included the following:

- Increased truck parking on the urban fringe to allow truck operators to position themselves to make delivers in the urban area.

- Lengthened acceleration/deceleration lanes to better accommodate the performance of trucks.

- Added additional lanes to the existing highway system.

- Established a system of terminals on the urban fringe for staging and transferring freight to delivery vehicles.

- Expanded the existing bridge anti-icing system to cover more bridges.

- Created overnight parking facilities in the urban core area to reduce inbound trucks in the morning peak.

- Integrated the traffic signal control systems across suburban and urban city and county boundaries to promote signal system coordination and improved inter-jurisdictional traffic management.

\subsubsection{Candidate planning strategies}

There were only four planning strategies. They include the following:

- Infrastructure design guidance to local governmental agency for the development of infrastructure that could better accommodate trucks.

- Legislation to hold first responder harmless from liability when removing cargo and vehicles from the scene of an incident.

- Develop system to collect continuous truck traffic information to support better planning of transportation system.

- Create a freight advisory committee at the Metropolitan Planning Organization (MPO) level to support better planning for transportation facilities to support freight.

\section{Selection and implementation of most promising}

Through a work shop with several transportation professionals from state and local transportation agencies, from trucking firms, and enforcement agencies, the candidate strategies were prioritized to identify the most promising. Following the ranking of the strategies, implementation plans were developed for the top five ranked strategies. The following subsections describe each of these strategies and implementation plans. 


\subsection{Zoning and roadway design guidance for local governments in and around heavy truck traffic generators}

The Twin Cities metropolitan area includes 197 local governments and each has some responsibility for land use control and development of transportation facilities. The land use controls and design standards for roadway plans and specification generally do not take into account the special requirements of large trucks. Local street designs generally focus on passenger cars and traffic control system designs to accommodate the performance characteristics of passenger vehicles rather than large combination trucks or even light duty combination vehicles and large straight trucks. In most situations, the percentage of trucks in the traffic stream is small enough that an occasional inability to accommodate the performance or dimensions of a truck is not a safety issue. For example, Figure 1 shows an island forming the throat for a right turn-in and right turn-out for a shopping center parking lot. Although automobiles can traverse the access and egress lanes, a truck cannot. The developer was given permission to develop the facility without another access point for trucks making deliveries to the grocery store in the shopping center. Trucks leaving the parking lot off-track and the rear trailer tires ride over the curb and onto the grass island. In this case, the inadequate turning radius only creates an unsightly broken curb and ruts in the mud, not to mention damage to goods in the trailer from the jostling this causes. However, a tight turning radius at a high pedestrian location can create a significant safety problem.

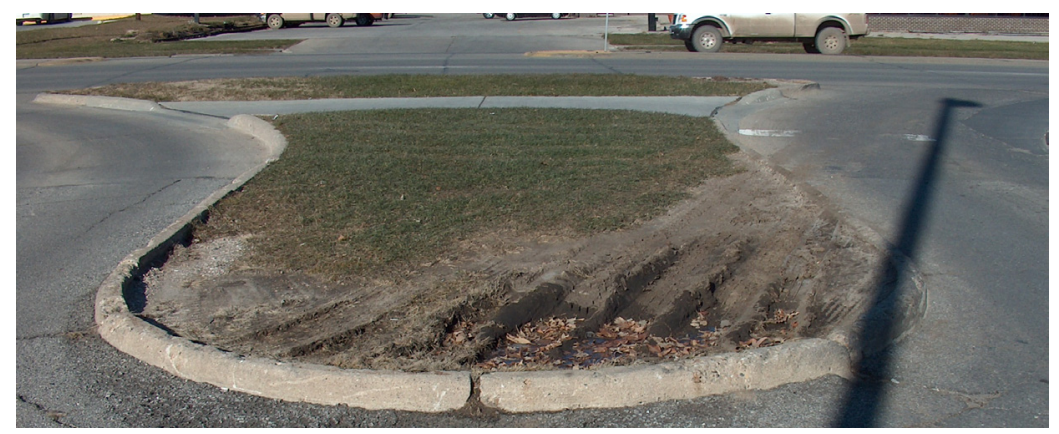

Figure 1: Inadequate-turning radius for trucks.

To support local governmental agencies, it was recommended that the state develop model zoning ordinances for development involving truck traffic generators and model plans and specifications for roads and streets adjacent to truck traffic generators that local agencies can adopt in part or entirely.

\subsection{Hold harmless legislation to strengthen quick clearance incident management}

The term quick clearance is used in incident management as a process to quickly remove wreckage, debris, and other elements from roadway path and establish 
normal traffic flow as quickly as possible. For example, in Figure 2, see a backhoe picking-up wrecked trailer parts and cargo off the pavement and loading it into the trash dumpster to remove cargo and restore Freeway operation. In Minnesota, enforcement agencies have the authority to remove vehicles and cargo blocking the roadway, but they are not held harmless from liability for damage done to the vehicle or cargo. As a result, the owner or the owner's agent remove most crashes involving a disabled truck, rather than the public agencies that are first on the scene. Waiting for the owner to respond, creates additional delay. Although state Motor Carrier Associations across the country have supported state level legislation to hold first responders harmless, the Minnesota Trucking Association has opposed holding responders harmless and has thwarted legislation in Minnesota in the past. The proposed strategy is to have the STA and enforcement agencies work with the Minnesota Trucking Association and other agencies to reach a compromise on proposed legislation.

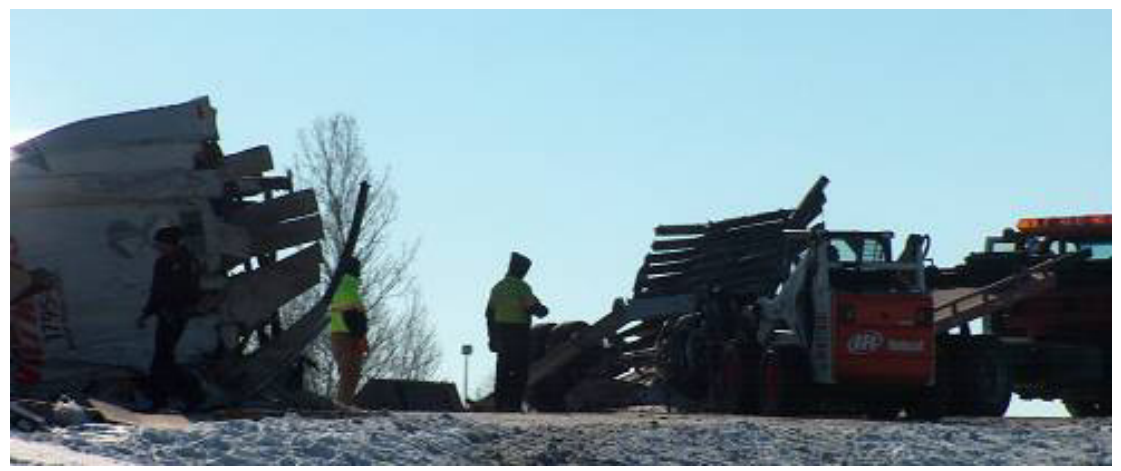

Figure 2: $\quad$ Small back hoe removing spilled cargo from freeway.

\subsection{Increasing commercial vehicle parking supply on the urban fringe}

Trucks making deliveries into the Twin Cities fill the rest areas along the Interstate systems to capacity nearly every night. Trucks unable to find parking in these public rest areas often spill over and park on Freeway ramps, parking lots, and other undesirable locations while the driver rests and waits to make a delivery within the urban area. The inadequate quantity of parking continues to be a problem that the trucking industry, through the American Trucking Associations, the Commercial Vehicle Safety Alliance, and the Owner-Operators Association, has asked the U.S. Department of Transportation [5] and its state partners to relieve. To better understand the deficiencies of truck parking supply in the Twin Cities area, the research suggested conducing a study of the truck traffic into the twin cities, and mapping the origins and destinations of trucks currently using public and private parking spaces in and around the Twin Cities to help determine the quantity and location of future parking while continuing to work with private sector partners (e.g., truck stops and trucking companies) to find private-public opportunities to solve the truck parking problem. 


\subsection{Advanced guide signage for freeway entrances}

The Freeway system in the Twin Cities has several different designs for interchanges and depending on the configuration of the ramps, the trucks wishing to enter the freeway should either approach ramp intersections from the arterial streets in the right most lane or the left most lane. To illustrate what is meant by this different Interchange design, see Figure 3. On the left of Figure 3 is a diamond interchange and on the right is a folded diamond interchange. If a vehicle is northbound on the arterial street (crossing over the Freeway) and wishes to turn west on the Freeway, the vehicle should be in the left lane of the arterial street at the diamond interchange. In the folded diamond case, a northbound to west movement should be made from the right lane. However, the guide signing for both of these interchanges is the same. Unless the driver is familiar with the interchange it is impossible to know whether the vehicle should be positioned in the right or left lane.
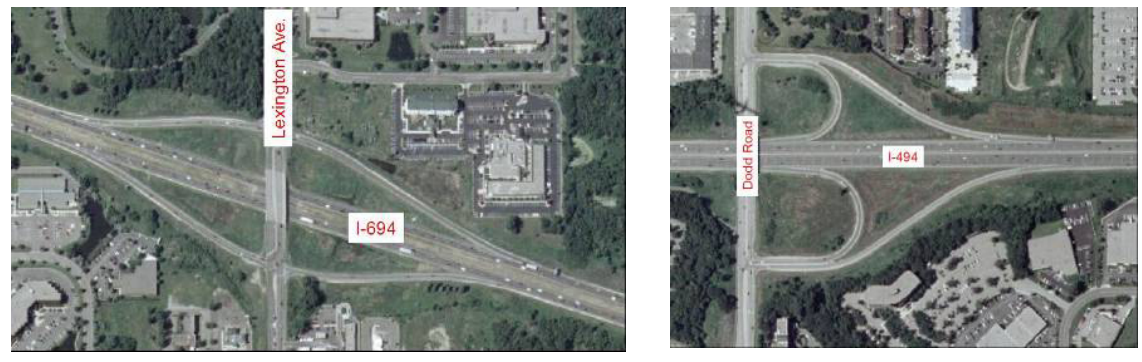

Figure 3: Aerial photo of a diamond and folded diamond interchange.

Not knowing which lane to position the truck results in confusion, potential for vehicle conflicts, and trucks having to travel through the ramp terminal intersection more than once. The research recommended that the Minnesota DOT adopt a more aggressive signage standard for intersection guide signs, modifying guide signs at interchanges with the highest volume of heavy vehicles first.

\subsection{Longer and truck-friendly acceleration and deceleration lanes}

This strategy deals with three separate road design features: 1) Deceleration lanes, 2) acceleration lanes, and 3) median acceleration lanes. Acceleration and decelerations lanes have been shown to greatly enhance intersection safety by segregating speed change lanes from through lanes.

In general, design guidance for the length of acceleration and deceleration lanes is based on performance characteristics of passenger cars and not trucks. The American Association of State Highway and Transportation Officials (AASHTO) "A Policy of Geometric Design of Highways and Streets," (the Green Book) [6] assumes a deceleration rate of $-11.2 \mathrm{ft} / \mathrm{sec}^{2}$. This braking rate is considered a comfortable rate of deceleration on wet pavement. Semi-tractor- 
trailer combination trucks equipped with antilock braking system (ABS) can achieve deceleration rates in controlled braking nearly equal to the rate the Green Book uses for passenger cars and in the most recent Vehicle Inventory and Use Survey of 2002 [7] only 60 percent of the truck in the fleet had ABS. Thus, current acceleration lane length guidance is only marginally adequate for trucks with ABS, and insufficient for the 40 percent of the truck fleet that does not have ABS.

Acceleration lane length guidelines are similarly insufficient. The length of an acceleration lane is intended to allow vehicles to accelerate to the operating speed of the facility. The length of the acceleration lane necessary for trucks to accelerate to the operating speed of the highway is typically related to the truck weight-to-horsepower ratio. NCHRP project 15-21 [8] collected weight-topower ratio information from trucks at weigh stations in three states. The weight-to-horsepower (lbs/hp) ranged from 60 to $400 \mathrm{lbs} / \mathrm{hr}$. The $85^{\text {th }}$ percentile weight-to-horse power ratio for trucks on freeways was found to be in the range of 170 to $210 \mathrm{lbs} / \mathrm{hp}$. In other words, only 15 percent of the fleet have a higher weight-to-power ratio. The same project estimated that to accelerate within the lane lengths specified by the Green Book trucks should have a weight-tohorsepower ratio ranging from 110 to 140 pounds/hp. Further, the authors estimate that the lane lengths need to be increased by 1.8 times over the Green Book recommendation to be able to accommodate the $85^{\text {th }}$ percentile truck.

A drawing of a median acceleration lane (MAL) is shown in Figure 4. At median divided highways, the MAL provides additional refuge for trucks and other vehicles in the median, and provides more opportunity for vehicles to accelerate into smaller gaps in high speed and high volume traffic. Ten of these lanes have been constructed in Minnesota to date and an evaluation of MALs by Janson [9] identified their positive impacts on safety and reduced delay.

The research recommended that high truck volume intersections should be identified and longer acceleration and deceleration lanes and MALs should be constructed at those locations.

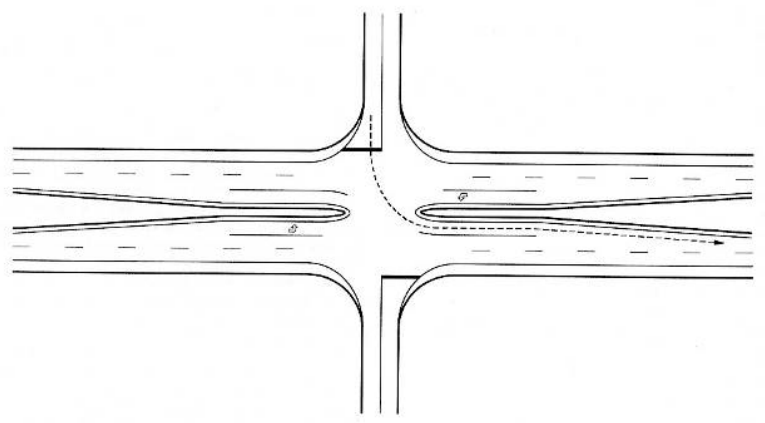

Figure 4: Median acceleration lane. 


\section{Conclusions}

The research described in this paper made general recommendations of strategies that should be applied by the Minnesota Department of Transportation and its partner transportation agencies in the Twin Cities metropolitan area. All of the recommendations are activities which can be accomplished in a fairly short time frame (less than five years), all will improve the follow of truck traffic in and through the Twin Cities, and none require large capital investments.

\section{Reference}

[1] Maze, T.H., D. Kroeger, and M.J. Berndt, Twin Cities Truck Traffic Management, Prepared for the Minnesota Department of Transportation, St. Paul, MN, 2005.

[2] Douglas, J.G., Strategies for Managing Increasing Truck Traffic; A Synthesis of Highway Practice, National Cooperative Research Program Synthesis Report 314, Washington, D.C., 2003.

[3] Minnesota Department of Trade and Economic Development, Minnesota: World Competitor, St. Paul, MN, 2005.

[4] Schrank, D. and T. Lomax, The 2004 Urban Mobility Report," prepared by the Texas Transportation Institute, Texas A\&M University, College Station, TX, 2004.

[5] Federal highway Administration, Report to Congress: Study of Adequacy of Parking Facilities, U.S. Department of Transportation, Washington, D.C., 2002.

[6] A Policy on Geometric Design of Highways and Streets, American Association of State Highway and Transportation Officials, Washington, D.C., 2001.

[7] Vehicle Inventory and Use Study, U.S. Census Bureau, Washington, D.C., 2004.

[8] Harwood, D.W., D.J.Torbic, K.R. Richard, W.D. Glauz, and L. Elefteriadou, Review of Truck Characteristics as Factors in Roadway Design, National Cooperative Research Program Report 505, Washington, D.C., 2003.

[9] Janson, C., Median Acceleration Lane Study Report, Rochester, Minnesota: Minnesota Department of Transportation, 2002. 